Everett's wishes, his widow threw out his cremated remains in the rubbish. His daughter, who had schizophrenia and married an addict, became addicted to alcohol and drugs herself and later committed suicide.

The Many Worlds of Hugh Everett III is short on critical analysis and slightly long on sordid details. There is much championing of Everett and his theories. Byrne's opinions can be heavy-handed, and he casts Bohr and Wheeler as villains. He strains hard to find meaning, proposing that the story of Everett's flamboyant mother Katherine, a pulp-fiction writer with manic depression, "captures the difficulty of being a self-reliant woman in mid 20th century America", and that Everett's life "reflects America's collective personality during the Cold War and beyond".

Byrne does not clearly explain why most scientists find Everett's interpretation to be over the top. "It's an extravagant violation of Occam's Razor," as one of my physicist colleagues puts it. Why postulate uncountable infinities of unknowable, branching universes to address a problem for which there are solutions that prune the branches? Everett's idea is merely an interpretation; it fails to make predictions and cannot be falsified.

The many worlds theory is still garish after all these years. Nevertheless, it is fascinating to read the story of its creator, himself too obsessed with models to intersect effectively with the real world.

Robert $\mathbf{P}$. Crease is professor of philosophy at Stony Brook University, 213 Harriman Hall, Stony Brook, New York 11794-3750, USA. He is author of The Great Equations and J. Robert Oppenheimer: A Life.

e-mail: rcrease@notes.cc.sunysb.edu

\title{
Soft-matter miracles
}

\author{
Matière sensible: Mousses, gels, cristaux \\ liquides et autres miracles \\ (Sensitive Matter: Foams, Gels, Liquid \\ Crystals and Other Miracles) \\ by Michel Mitov \\ Seuil: 2010.179 pp (in French). €18
}

Soft-matter research investigates ambiguous states of matter, the paradoxical properties of which rely on the art of mixture. An emulsion formed simply of oil and water plus a few molecules of detergent gains the stability of a cream. Similarly, foam produced from air bubbles in soapy water transforms those two fluids into an almost-solid state. In Matière sensible, liquid-crystal researcher Michel Mitov marvels at the surprising behaviour of these materials.

Rather than naming the book after his discipline, Mitov uses the title 'sensitive matter.'The expression 'soft matter' was coined as a joke in the 1970s by physicist Madeleine Veyssié indeed, the French term matière molle sounds sleazy. However, it acquired a majesty when physicist PierreGilles de Gennes chose it as the title of his Nobel lecture in 1991. From then on, the scientific community was converted.

Mitov's book, in French, begins with a description of emulsions, foams, polymer solutions, gels and colloids. He introduces their first sensitive quality - that tiny quantities of additives can dramatically alter the properties of a liquid. Bubbles and foams are created by adding less than one-tenth of a gram of soap to a litre of water. This blocks the gravitational drainage that would otherwise make these constructions collapse in a fraction of a second. Firemen know that a similar concentration of long polymer chains in water makes jets of the fluid twice as powerful by reducing turbulence in the hose. Remarkably, both of these examples remain partly unexplained: in this field, art often precedes understanding by decades.

The book reveals another form of sensitivity - that many of these critical architectures are easily disrupted. Small causes can generate big effects. Mitov explains how foam can be destroyed by hydrophobic particles; shampooing hair for a second time, for example, gives more lather than the first because the dirt particles have been removed. He also explains how tiny changes in $\mathrm{pH}$ or temperature can destroy the lipid capsules that surround many drugs. It is this controlled disintegration that allows drug delivery to specific places in the body.

The control of soft matter is even more fascinating than its architecture. Mitov describes the miracle of San Gennaro, a ritual that has taken place three times a year since 1389 in Naples cathedral, Italy. In the ceremony, a sealed glass

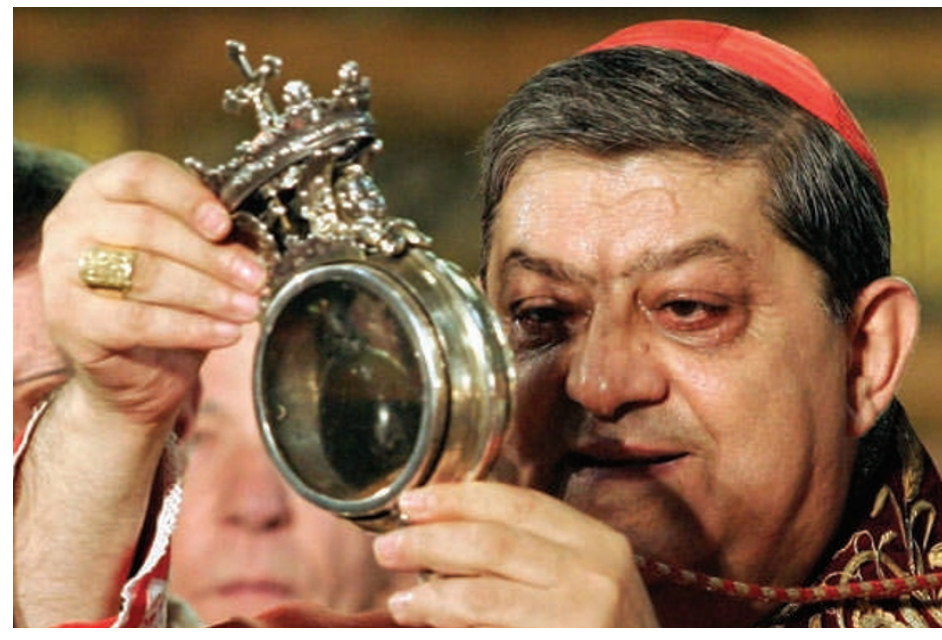

San Gennaro's 'blood' may owe its liquefaction to the quirks of soft matter. ampoule is displayed to the faithful. It contains a brown solid that is said to be the blood of San Gennaro. At the end of the ceremony, the substance often liquefies into a soft gel that looks like wet blood. Mitov describes witnessing the ritual and puzzles at how the miracle works.

The phenomenon is seasonal, the blood being more fluid in warmer weather, implying that the brown material might be temperaturesensitive. Alternatively, the gel's fluidity may be driven by manipulation of the ampoule, as is the case for some Bingham fluids that flow above a given stress, or for thixotropic liquids whose viscosity can decrease as stress increases. Mitov suggests centuries-old recipes for materials that give such behaviour, including spermaceti - a waxy lipid extracted from whales' heads - or clay solutions. But he ultimately allows uncertainty to persist, suggesting only that the sacred 'blood' might contain a blend of both elements.

This emblematic example shows how subtle and smart a complex fluid can be, and illustrates the challenge of understanding these diverse materials. Mitov doesn't say much about the future of soft-matter research. But his book ably reflects a goal of the field - to extract beautiful intellectual challenges from 'dirty' industrial or everyday questions. Matière sensible is an excellent guide to the labyrinthine world of soft matter.

David Quéré is professor of physics at the École Polytechnique, 91128 Palaiseau, France, and a senior scientist at CNRS/ESPCl, 10 Rue Vauquelin, Paris, France. He is co-author of the book Capillarity and Wetting Phenomena: Drops, Bubbles, Pearls, Waves. e-mail: david.quere@espci.fr 